\title{
Protein hydrolysates from boarfish (Capros aper) and Atlantic salmon (Salmo salar) skin gelatin improve metabolic control in genetically obese diabetic $(o b / o b)$ mice
}

\author{
Vadivel Parthsarathy ${ }^{a \dagger}$, Chris M. McLaughlin ${ }^{\mathrm{a}}$, Shaun J. Sharkey ${ }^{\mathrm{a}}$, Pádraigín A. Harnedy-Rothwellc, \\ Ryan A. Lafferty ${ }^{\mathrm{a}}$, Philip J. Allsopp ${ }^{\mathrm{b}}$, Emeir M. McSorley ${ }^{\mathrm{b}}$, Richard J. FitzGerald ${ }^{\mathrm{c}}$ \\ and Finbarr P.M. O'Harte $\mathrm{a}^{*}$
}

\begin{abstract}
aDiabetes Research Group, School of Biomedical Sciences, Ulster University, Coleraine, Co. Derry, BT52 1SA, Northern Ireland
${ }^{b}$ Nutrition Innovation Centre for Food and Health, School of Biomedical Sciences, Ulster University, Coleraine, Co. Derry, BT52 1SA

Northern Ireland, UK

'Department of Biological Sciences, University of Limerick, Castletroy, Limerick, Ireland

*Corresponding author: Finbarr P.M. O’Harte, Diabetes Research Group, School of Biomedical Sciences, Ulster University, Coleraine, Co. Derry, BT52 1SA, Northern Ireland. Tel: +44 (0) 28 70124853; E-mail: fpm.oharte@ulster.ac.uk

DOI: $10.31665 /$ JFB.2021.16292

Received: November 29, 2021; Revised received \& accepted: December 23, 2021

Citation: Parthsarathy, V., McLaughlin, C.M., Sharkey, S.J., Harnedy-Rothwell, P.A., Lafferty, R.A., Allsopp, P.J., McSorley, E.M., FitzGerald, R.J., and O'Harte, F.P.M. (2021). Protein hydrolysates from boarfish (Capros aper) and Atlantic salmon (Salmo salar) skin gelatin improve metabolic control in genetically obese diabetic $(o b / o b)$ mice. J. Food Bioact. 16: 48-57.
\end{abstract}

\begin{abstract}
There is increasing interest in dietary protein for management of Type 2 diabetes mellitus (T2DM) and obesity. The effects of twice-daily oral administration of a salmon skin gelatin hydrolysate (SSGH, $50 \mathrm{mg} / \mathrm{kg}$ ), boarfish protein hydrolysate (BPH, $(50 \mathrm{mg} / \mathrm{kg})$, metformin $(200 \mathrm{mg} / \mathrm{kg})$, or saline control, were investigated in ob/ob mice. Non-fasting blood glucose was significantly reduced with SSGH $(p<0.01)$, BPH $(p<0.001)$ and metformin $(p<$ $0.001)$, which were reflected in reductions in glycated haemoglobin $\left(\mathrm{HbA}_{1 \mathrm{c}}\right)(\mathrm{p}<0.001, \mathrm{p}<0.01$ and $\mathrm{p}<0.01$, respectively). Responses to oral and intraperitoneal glucose tolerance were improved ( $<0.05-0.01)$, as well as circulating plasma lipid profiles $(p<0.05-0.001)$. Chronic BPH treatment increased circulating plasma insulin $(p<$ $0.01)$, whereas SSGH improved insulin sensitivity $(p<0.05)$, versus respective controls. All treatments significantly reduced energy intake $(p<0.05-0.001)$ versus $(o b / o b)$ controls, without affecting overall bodyweight. These findings suggest that fish hydrolysates mediate potent anti-diabetic actions similar to metformin and might be suitable for the management and prevention of T2DM.
\end{abstract}

Keywords: Boarfish; Blood glucose; Functional food; Protein hydrolysate; Salmon skin gelatin; Type 2 diabetes mellitus.

\section{Introduction}

The global incidence of type 2 diabetes mellitus (T2DM) and obesity continue to increase exponentially. Despite substantial efforts to promote a clear public health message targeted at dietary/ lifestyle interventions in the early stages of the treatment of these metabolic diseases, preventative strategies often remain ineffective (Cho et al., 2018; Kalra et al., 2021). There is increasing inter- est in alternative approaches for favourably modulating glycaemic control and appetite, to reduce the incidence of obesity and the associated risk of developing T2DM. Dietary protein and enzymatic hydrolysates isolated from food-derived proteins including fish sources have been reported to modulate glycaemic control and exert satiating activities (Rivero-Pino et al., 2020; Sharkey et al., 2021). This led to emerging interest in the development of protein/ peptide based functional food ingredients to beneficially modulate glycaemic control and excessive weight gain and reduce the risk 
of metabolic dysregulation associated with T2DM and obesity. Proteins/peptides have been shown to stimulate incretin hormones such as GLP-1 and GIP in the gut and inhibit DPP-4 mediated incretin hormone degradation, all of which help facilitate and enhance post-prandial insulin response and improved glycaemic control (Cudennec et al., 2012; Harnedy et al., 2018a; Harnedy et al., 2018b; Harnedy et al., 2017; Parthsarathy et al., 2018).

The bioactivity of protein/peptides components is heavily dependent on the nature and structure of the intact protein. For example, collagen hydrolysates have been found to produce a more reliable anti-diabetic activity compared to muscle hydrolysates due to repetitive proline-rich sequences within collagen. The latter is thought to be an important characteristic for the inhibition of the ubiquitous serine N-terminal dipeptidase dipeptidyl peptidase-4 (DPP-4) responsible for the inactivation of these beneficial incretin hormones GLP-1 and GIP (Drummond et al., 2018; Nongonierma and FitzGerald, 2019; Zhu et al., 2010).

One of the primary motivations for utilisation of marine protein, is an increasing desire for a sustainably sourced high-quality protein to meet a growing population and increasing global demand. The fishing industry is under increasing strain from overfishing and the demand for eco-friendly disposal of waste (Le Pape et al., 2017). Despite advances in fish processing and distribution practices, reports indicate that the seafood industry worldwide generated 19.7 million tonnes of fish processing by-products, alongside non-target low value landed fish in 2016 (FAO, 2020). Therefore, focus has shifted to utilisation of fish processing byproducts to minimise food wastage and the use of less common marine protein sources to alleviate pressure on more commonly sought-after sources (Harnedy-Rothwell et al., 2021b). In general, fish and shellfish processing by-products are utilised as low-value animal and farmed fish/shellfish feed, pet food, fertilizer, and as a source for energy generation and fish oil (FAO, 2020; Välimaa et al., 2019). However, high-quality dietary protein derived from by-products of popular fish stocks or underutilised sources, could provide much-needed relief for endangered species, while also improving the dietary quality of the global population.

Salmon protein hydrolysates have previously exhibited effective anti-diabetic potential both in vitro and in vivo. Salmon skin gelatin and muscle protein hydrolysates were found to have in vitro DPP-4 inhibitory activity by Li-Chan et al., (2012), and these effects were corroborated by Neves and colleagues, who found similar effects with Atlantic salmon hydrolysates (Harnedy et al., 2017; Neves et al., 2017a; Neves et al., 2017b). Furthermore, peptide fractions of salmon protein hydrolysates promoted insulin-dependent glucose uptake in L6 myocytes (Roblet et al., 2016). Our own studies have previously shown that salmon skin gelatin and protein hydrolysates generated with Alcalase ${ }^{\circledR} 2.4 \mathrm{~L}$ and Flavourzyme ${ }^{\circledR}$ $500 \mathrm{~L}$ potently stimulates insulin secretion from pancreatic $\beta$-cells (with associated increases in intracellular calcium and changes in membrane potential, downstream signalling markers of stimulation), as well as stimulating GLP-1 secretion from GLUTag cells (Harnedy et al., 2018a). In in vivo studies, incorporation of salmon protein hydrolysate, when incorporated into a high-sugar, high-fat diet, led to improved insulin sensitivity and glucose tolerance (Pilon et al., 2011). Peptides derived from salmon skin gelatin hydrolysates have also been shown to reduce blood glucose in diabetic rats through GLP-1 stimulation and a reduction in islet cell apoptosis (Hsieh et al., 2015; Zhu et al., 2010; Zhu et al., 2017).

While boarfish has been investigated considerably less, our previous in vitro research showed that boarfish protein hydrolysates $(\mathrm{BPH})$ potently stimulates insulin secretion from pancreatic $\beta$-cells (increasing intracellular calcium and membrane potential). In addition, BPH promotes GLP-1 release from GLUTag cells, glucose uptake in differentiated 3T3-L1 mouse fibroblasts (which display adipocyte characteristics) and inhibits DPP-4 activity ( $\mathrm{IC}_{50} 1.18$ $\mathrm{mg} / \mathrm{mL}$, Parthsarathy et al., 2018). Furthermore, peptides identified from BPH were found to exert both insulin-secretory and DPP-4 inhibitory activities, indicating that these peptides could be exerting anti-diabetic activity through multiple mechanisms (Harnedy-Rothwell et al., 2020). Interestingly, the most successful hydrolysates in vitro in our research were both generated using Alcalase ${ }^{\circledR}$ 2.4L and Flavourzyme ${ }^{\circledR}$ 500L. As found in the molecular mass distribution, the vast majority of peptides in these hydrolysates had a Mw of $<1 \mathrm{kDa}$. This agrees with the suggestion that small molecular weight peptides (SMWP's) produce more potent bioactivity, and when reassessed after simulated gastrointestinal digestion (SGID), there was little change in bioactivity. Additionally, when subjected to thermal stress as part of incorporation into a food product $\left(90^{\circ} \mathrm{C}\right.$ for $1 \mathrm{~min}, 121^{\circ} \mathrm{C}$ for $\left.42 \mathrm{~s}\right)$, there was no effect on in vitro DPP-4 activity of the $\mathrm{BPH}$, and no increase in susceptibility to SGID (Harnedy-Rothwell et al., 2021a).

Thus, the aim of the present study was to determine the effect of both the salmon skin gelatin hydrolysate and boarfish protein hydrolysate generated with Alcalase ${ }^{\circledR} 2.4 \mathrm{~L}$ and Flavourzyme ${ }^{\circledR}$ 500L, which showed promising anti-diabetic activity in vitro, in a relevant genetic $(o b / o b)$ mouse model of obesity-diabetes. Specifically, the aim was to determine if these fish hydrolysates retained bioactivity in the GIT and exerted a measurable benefit in diabetes and obesity parameters, such as blood glucose, bodyweight, energy intake, $\mathrm{HbA}_{1 \mathrm{c}}$, plasma insulin, plasma GLP-1 and insulin sensitivity.

\section{Materials and methods}

\subsection{Materials and chemicals}

Samples of Atlantic salmon (Salmo salar) skin was kindly provided by The Good Fish Processing Company Ltd., Carrigaline, Co. Cork, Ireland and minced deboned boarfish were kindly provided by Killybegs Fishermen's Organisation, Killybegs, Co. Donegal, Ireland on behalf of Bord Iascaigh Mhara (BIM). Dglucose and sodium chloride $(\mathrm{NaCl})$ were purchased from $\mathrm{BDH}$ Chemicals Ltd. (Poole, Dorset, UK). Alcalase ${ }^{\circledR} 2.4 \mathrm{~L}$ and Flavourzyme ${ }^{\circledR} 500 \mathrm{~L}$, insulin from bovine pancreas (I6634) and di-methyl biguanide hydrochloride (metformin) (D150959) were obtained from Sigma Aldrich (Poole, Dorset, UK). Other consumables (syringes, needles, etc.) were obtained from Becton Dickinson (Plymouth, Devon, UK).

\subsection{Generation of salmon skin gelatin (SSGH) and boarfish protein (BPH) hydrolysates by enzymatic hydrolysis.}

Salmon skin gelatin was extracted using an optimised protocol as described by Harnedy et al., (2018a). In brief, residual salmon meat was removed from the skin by stirring in $0.2 \mathrm{M} \mathrm{NaOH}(1: 5$, $\mathrm{w}: \mathrm{v})$ at room temperature for $15 \mathrm{~min}$. This process was repeated three times and the skin was then washed with distilled water, until a neutral $\mathrm{pH}$ was reached, the skin was retained by filtration through a double layer of cheesecloth between each treatment. The collagen in the skin was converted to gelatin during $1 \mathrm{~h}$ stirring at room temperature following its adjustment to $\mathrm{pH} 3.0$ using $1.0 \mathrm{M}$ $\mathrm{HCl}$. The skin was brought back to neutral $\mathrm{pH}$ by soaking the skin for $15 \mathrm{~min}$ in distilled water $(1: 5(\mathrm{w} / \mathrm{v}))$ with separation between each wash $(\times 3)$ as described above. The gelatin in the swollen skin was then extracted in distilled water (1:5,w:v) during heating at 
$50^{\circ} \mathrm{C}$ for $16 \mathrm{~h}$. The gelatin-containing supernatant was retained, freeze-dried (FreeZone 18L, Labconco, Kansas City, MO, USA) and stored at $-20^{\circ} \mathrm{C}$ until required.

Salmon skin gelatin and boarfish protein hydrolysates were prepared using the optimised hydrolysis protocols described previously by Harnedy et al. (2018a) and Parthsarathy et al. (2018), respectively. Briefly, 7\% (w/v (dry weight)) gelatin solution and $6.83 \%(\mathrm{w} / \mathrm{v})$ homogenised boarfish protein solution (prepared by homogenised (x4) of minced boarfish meat in distilled water at $24,000 \mathrm{rpm} / \mathrm{min}$ for $15 \mathrm{sec}$ ) was preheated to $50^{\circ} \mathrm{C}$ and adjusted to $\mathrm{pH} 7.0$ and sequentially hydrolysed (over $4 \mathrm{~h}$ ) with Alcalase $2.4 \mathrm{~L}$ and Flavourzyme 500L at an enzyme:substrate (E:S) ratio of $0.74 \%$ $(\mathrm{v} / \mathrm{w})$ for salmon skin gelatin and $0.67 \%(\mathrm{v} / \mathrm{w})$ for the boarfish protein suspension. The enzymes were inactivated by heating at $90^{\circ} \mathrm{C}$ for $20 \mathrm{~min}$. The boarfish derived peptides were then separated by double filtration (Whatman grade 1: $11 \mu \mathrm{m}$ ). Both hydrolysates were freeze-dried (Labconco) and stored at $-20^{\circ} \mathrm{C}$ until required.

\subsection{Experimental animals}

All animal experiments were carried out in accordance with the UK Animals (Scientific Procedures) Act 1986 and EU Directive 2010/63EU for animal experiments and approved by Ulster University Animal Welfare and Ethical Review Board. All necessary steps were taken to prevent any potential animal suffering. B6.VLep $^{\mathrm{ob}} / \mathrm{OlaHsd}$ mice (Envigo Ltd, Blackthorne UK) were individually housed in an air-conditioned room $\left(22 \pm 2{ }^{\circ} \mathrm{C}\right)$ and on a 12 h light:dark cycle (08:00-20:00). Drinking water and standard rodent diet ( $10 \%$ fat, $30 \%$ protein, $60 \%$ carbohydrate; percent of total energy $12.99 \mathrm{~kJ} / \mathrm{g}$, Trouw Nutrition, Cheshire, UK) were provided ad libitum. Another group of age matched C57BL6/JOlaHsd mice were maintained on a standard rodent diet (as above) to act as healthy controls. The obese diabetic $(o b / o b)$ mouse is a well-established genetically induced model of diabetes and obesity which has been described previously (Nilsson et al., 2012).

\subsection{Chronic treatment \& study design}

Prior to experimentation, animals were assigned to groups based on their non-fasting blood glucose and bodyweight. Following grouping $(n=8)$, animals were acclimated to treatment by oral gavage with saline $(0.9 \% \mathrm{NaCl})$ twice daily $(09: 00$ and 17:00) for 6 days, prior to beginning the intervention. On Day 0 , mice received treatment with one of the following; saline vehicle $(0.9 \%$ $\mathrm{NaCl})$, salmon skin gelatin hydrolysate (SSGH) $(50 \mathrm{mg} / \mathrm{kg}$ bodyweight), boarfish protein hydrolysate $(\mathrm{BPH})(50 \mathrm{mg} / \mathrm{kg}$ bodyweight), or metformin $(200 \mathrm{mg} / \mathrm{kg}$ bodyweight). All treatments were delivered twice-daily orally (09:00 and 17:00) for 27 days in saline solution in a volume of $5 \mathrm{ml} / \mathrm{kg}$ bodyweight. Non-fasting blood glucose, bodyweight, plasma insulin and food intake were monitored at 3-day intervals. Blood samples were collected from the cut tip of the tail vein into chilled heparin/fluoride-coated microcentrifuge tubes (Sarstedt, Nümbrecht, Germany) and immediately centrifuged $(13,000 \mathrm{rpm} \times 10 \mathrm{~min})$. The resulting plasma was then aliquoted and stored at $-20^{\circ} \mathrm{C}$ for further analysis.

\subsection{Terminal analyses}

Glycated haemoglobin $\left(\mathrm{HbA}_{1 \mathrm{c}}\right)$ was measured using A1cNow kits (BHR, Nuneaton, UK) and all procedures were carried out according to manufacturer's instructions. Both oral and intraperitoneal (i.p.) glucose tolerance tests were performed in fasted mice. Mice were fasted overnight (minimum $12 \mathrm{~h}$ ). Whole blood glucose was measured via the cut tip of the tail vein using the handheld Ascencia Contour blood glucose meter (Ascencia, Berkshire, UK), prior to glucose administration ( $0 \mathrm{~min}$ ), and then $15,30,60,90$ and 120 $\mathrm{min}$ after glucose load (18.8 $\mathrm{mmol} / \mathrm{kg}$ bodyweight). As described in Section 2.4, whole blood was collected into chilled heparin/fluoridecoated microcentrifuge tubes for plasma hormone analysis. Mice were rested for several days to allow a washout period between oral and i.p. glucose tolerance tests. Plasma insulin was measured using an in-house radioimmunoassay (Flatt and Bailey, 1981).

Insulin sensitivity was assessed by fasting the mice overnight and measuring whole blood glucose immediately prior, and 30 and $60 \mathrm{~min}$ following i.p. injection of bovine insulin $(50 \mathrm{U} / \mathrm{kg}$ bodyweight). Lean saline controls were exempt from insulin sensitivity testing due to increased risk of hypoglycaemia in these animals.

For terminal blood collection, mice were placed under terminal anaesthesia and cardiac puncture was performed. This whole blood was aliquoted into chilled heparin/fluoride-coated microcentrifuge tubes and centrifuged (13,000 rpm x $10 \mathrm{~min})$.

Terminal plasma lipid analysis was carried out using the ILab 650 chemistry analyser (Diamond, MA, USA). Terminal plasma total GLP-1 was measured using a Millipore total plasma GLP1 ELISA kit (EZGLP1T-36K; Livingston, UK) according to the manufacturer's instructions.

\subsection{Statistical analysis}

All statistical analysis was carried out using Prism (v5.0, GraphPad Software Inc. CA, USA) and expressed as mean \pm S.E.M. Two-way or one-way Analysis of Variance (ANOVA) was used where appropriate, followed by the Student-Newman-Keuls or Bonferroni's post-hoc test, respectively. $\mathrm{p}<0.05$ was considered to indicate statistical significance.

\section{Results}

\subsection{Effects of BPH and SSGH on bodyweight, energy intake and metabolic markers}

Chronic oral administration over 27 days of either fish hydrolysate or metformin failed to have a significant effect on bodyweight in this obese diabetic $(o b / o b)$ mouse model (Figure 1a, b). However, by day 27 there was a significant reduction in cumulative energy intake of $16 \%$ following BPH, $11 \%$ with SSGH and $18 \%$ with metformin $(\mathrm{p}<0.001)$ versus the $(o b / o b)$ saline controls (Figure 1c). Administration of SSGH (but not BPH) caused a significant increase $(39 \%, \mathrm{p}<0.001)$ in terminal plasma total GLP-1, whilst metformin caused a $25 \%$ reduction $(\mathrm{p}<0.001)$ versus $(o b / o b)$ saline controls (Figure 1d).

\subsection{Effects of BPH and SSGH on non-fasting blood glucose and insulin}

As shown in Figure 2a and $\mathrm{b}$ a significant reduction in non-fasting blood glucose was induced by BPH $(37 \%$; $<<0.001)$, SSGH (33\%; $\mathrm{p}<0.01)$, and metformin $(38 \% ; \mathrm{p}<0.001)$. This was reflected by a trend towards an increase in plasma insulin concentration in each experimental group, which only reached significance ( $78 \%$ higher) in the BPH treated group (Figure 2c, d; $\mathrm{p}<0.01$ ). 

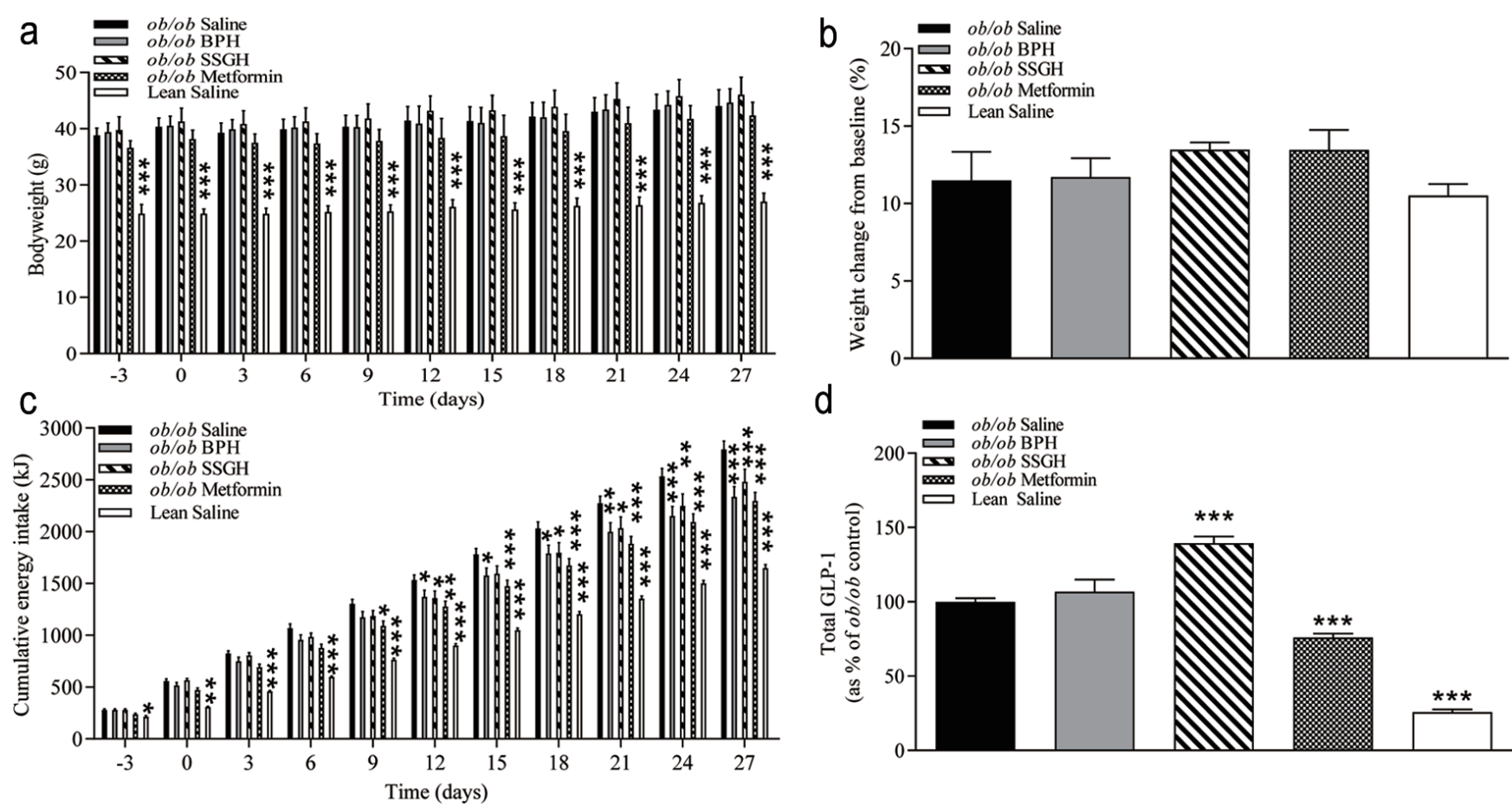

d

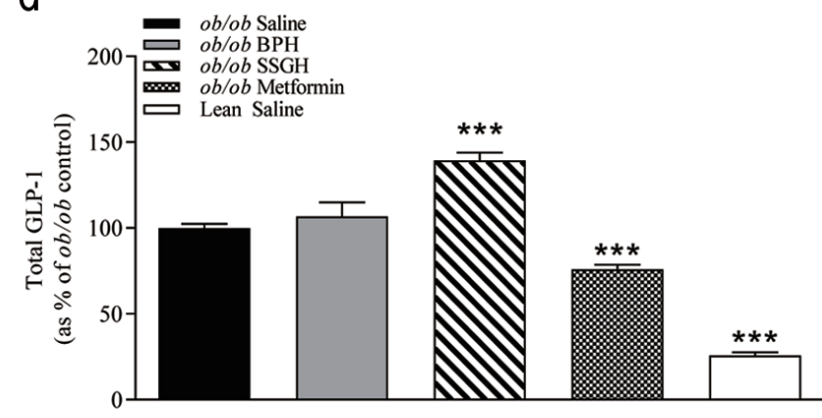

Figure 1. The effect of fish hydrolysate treatment on (a) bodyweight, (b) weight change, (c) energy intake and (d) plasma total GLP-1. Mice were treated with hydrolysate $(50 \mathrm{mg} / \mathrm{kg}$ bodyweight), saline, or metformin $(200 \mathrm{mg} / \mathrm{kg}$ bodyweight) twice daily for 27 days. Values represent mean \pm S.E.M. $(\mathrm{n}=8)$ ${ }^{*} \mathrm{p}<0.05,{ }^{* *} \mathrm{p}<0.01,{ }^{* * *} \mathrm{p}<0.001$ versus $(o b / o b)$ saline control. BPH: boarfish protein hydrolysate; SSGH: salmon skin gelatin hydrolysate; kJ: kilojoules.

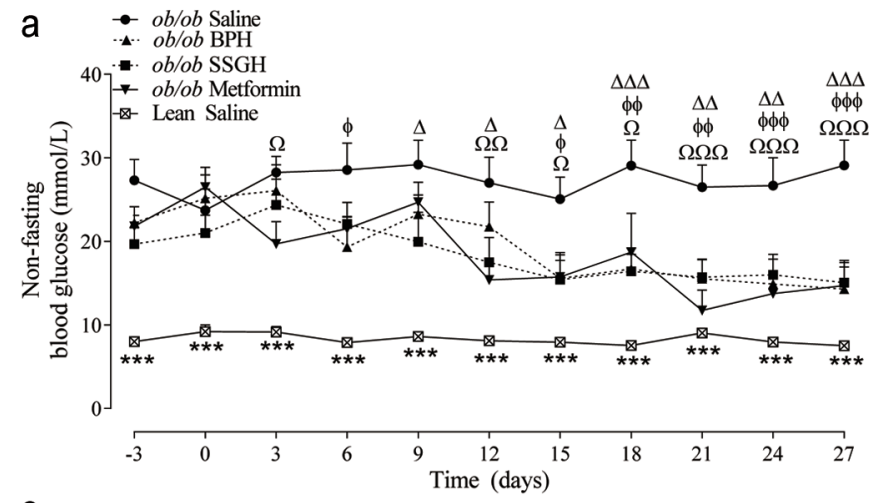

C

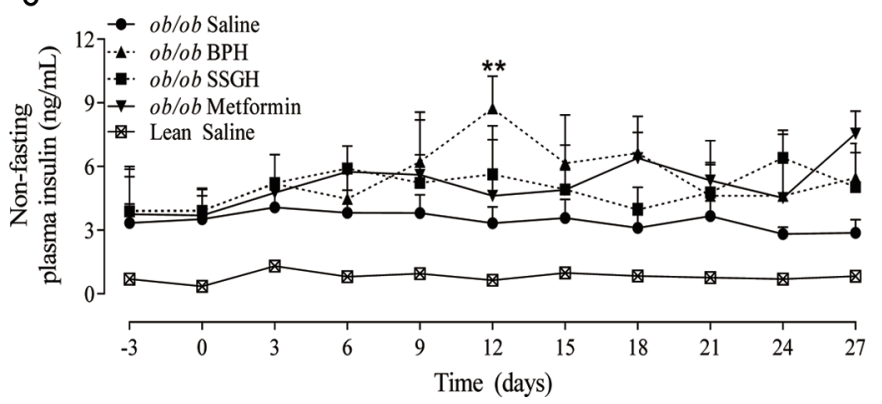

b

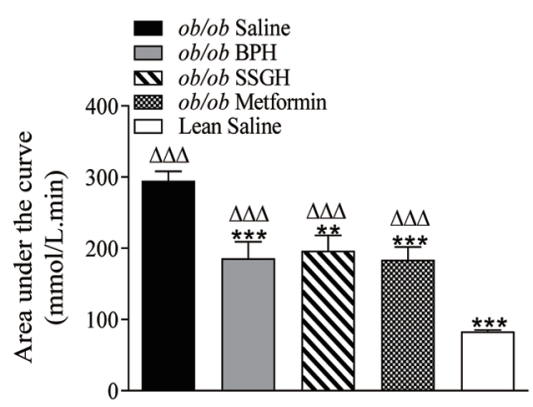

d

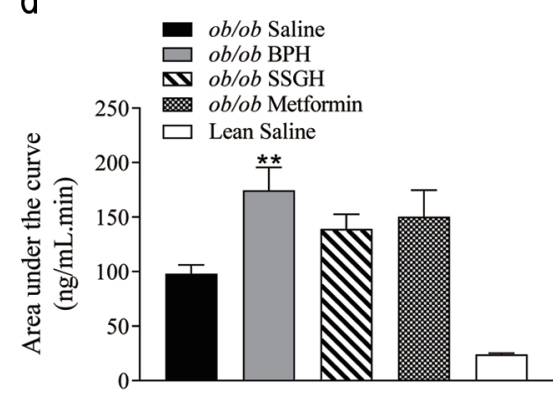

Figure 2. The effect of fish hydrolysate treatment on (a) blood glucose and (c) plasma insulin, with (b, d) respective calculated area under the curve values. Mice were treated with hydrolysate $(50 \mathrm{mg} / \mathrm{kg}$ bodyweight), saline, or metformin ( $200 \mathrm{mg} / \mathrm{kg}$ bodyweight) twice daily for 27 days. Values represent mean \pm S.E.M. $(n=8) .{ }^{* *} p<0.01,{ }^{* * *} p<0.001$ versus (ob/ob) saline control. ${ }^{\Omega} p<0.05,{ }^{\Omega} \Omega p<0.01,{ }^{\Omega} \Omega \Omega p<0.001$ versus metformin. ${ }^{\Delta} p<0.05,{ }^{\Delta \Delta} p<0.01,{ }^{\Delta \Delta \Delta} p$ $<0.001$ versus SSGH. $\phi_{\mathrm{p}}<0.05, \phi_{\mathrm{p}}<0.01, \phi \phi_{\mathrm{p}}<0.001$ versus BPH. BPH: boarfish protein hydrolysate; SSGH: salmon skin gelatin hydrolysate. 

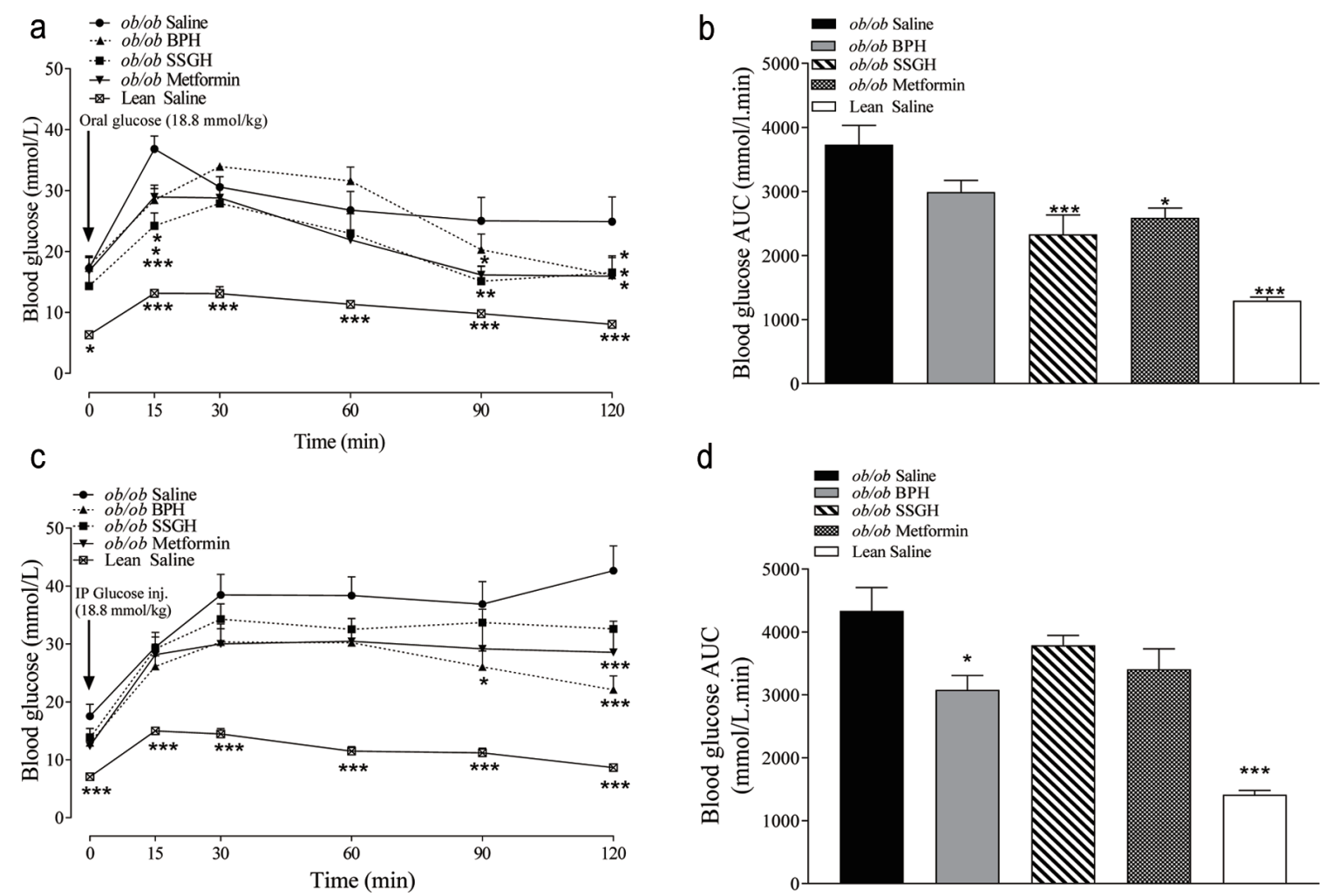

Figure 3. The effect of fish hydrolysate treatment on postprandial glucose control following (a) orogastric and (c) intraperitoneal glucose administration, with (b, d) respective calculated area under the curve. Mice were treated with hydrolysate ( $50 \mathrm{mg} / \mathrm{kg}$ bodyweight), saline, or metformin ( $200 \mathrm{mg} / \mathrm{kg}$ bodyweight) twice daily for 27 days, with glucose tolerance testing performed thereafter. Values represent mean \pm S.E.M. $(n=8) .{ }^{*} p<0.05,{ }^{* *} p<0.01,{ }^{* * *} p<$ 0.001 versus $(o b / o b)$ saline control. BPH: boarfish protein hydrolysate; SSGH: salmon skin gelatin hydrolysate.

\subsection{Effects of $B P H$ and SSGH on glucose tolerance, insulin sen- sitivity and $H_{b A_{1 c}}$}

Glucose tolerance was significantly improved after an OGTT with SSGH (AUC 38\% reduction; $\mathrm{p}<0.001)$ and metformin $(30 \%$; $\mathrm{p}<0.05)$, but not with BPH (21\%) (Figure 3a, b). Despite this, BPH $(26 \% ; \mathrm{p}<0.05)$ and metformin $(25 \% ; \mathrm{p}<0.05)$ caused a significant improvement in i.p. glucose tolerance (Figure 3c, d). Although SSGH and metformin caused a $13 \%$ and $19 \%$ reduction in blood glucose, respectively this failed to reach statistical significance (Figure 3c, d).

No change in whole body insulin sensitivity was found following the treatment interventions, except for the SSGH, which moderately improved insulin sensitivity versus the saline-treated $(o b / o b)$ controls (Figure 4a) but failed to reach significance. As shown in Figure $4 \mathrm{~b}$, treatment with BPH resulted in a significant reduction in basal fasting blood glucose $(43 \% ; p<0.05)$, but SSGH and metformin treatment groups failed to show a significant reduction (Figure 4b). All treatment groups displayed a significant reduction in glycated haemoglobin $\left(\mathrm{HbA}_{1 \mathrm{c}}\right)$ with $\mathrm{BPH}, \mathrm{SSGH}$ and metformin showing reductions of $32 \%(p<0.001), 26 \%(p<0.01)$, and $25 \%(\mathrm{p}<0.01)$, compared to saline treated $(o b / o b)$ controls, respectively (Figure 4c).

\subsection{Effect of BPH and SSGH on terminal plasma lipid profiles}

Plasma total cholesterol was significantly reduced following 27 day treatment with SSGH $(13 \%$; $p<0.05)$ and metformin $(15 \%$; $\mathrm{p}<0.01)$, whereas this parameter was lower in $\mathrm{BPH}(13 \%)$, but in the latter case this failed to reach significance (Figure 5a). As shown in Figure 5b, there was a significant reduction in plasma low-density lipoprotein (LDL) concentrations by $60 \%$ with BPH $(\mathrm{p}<0.001), 40 \%$ with SSGH $(\mathrm{p}<0.001)$ and $63 \%$ with metformin $(\mathrm{p}<0.001)$. Concurrently, there was no significant change in plasma high-density lipoprotein (HDL) concentrations among any of the treatment groups (Figure 5c). Finally, plasma triglyceride (TG) concentrations were reduced in all treatment groups, with a reduction by BPH $(30 \% ; \mathrm{p}<0.05)$, with SSGH $(38 \%$; $<<0.01)$ and by metformin $(40 \% ; \mathrm{p}<0.001)$ (Figure $5 \mathrm{~d})$

\section{Discussion}

The results of this study showed that oral administration of both $\mathrm{BPH}$ and/or SSGH twice-daily for 27 consecutive days resulted in a significant reduction in $\mathrm{HbA}_{1 \mathrm{c}}$, either i.p. or oral glucose tolerance, non-fasting blood glucose, with a corresponding increase in plasma insulin concentration. This was accompanied with no significant change in bodyweight but a reduction in energy intake over the study duration, indicating that the antidiabetic effects were unlikely to be completely dependent on the alleviation of obesity. Broadly speaking, similar antidiabetic effects were observed with both BPH and SSGH administration. Both BPH and SSGH had comparable reductions in non-fasting blood glucose, however, non-fasting plasma insulin was more elevated by BPH treatment, 

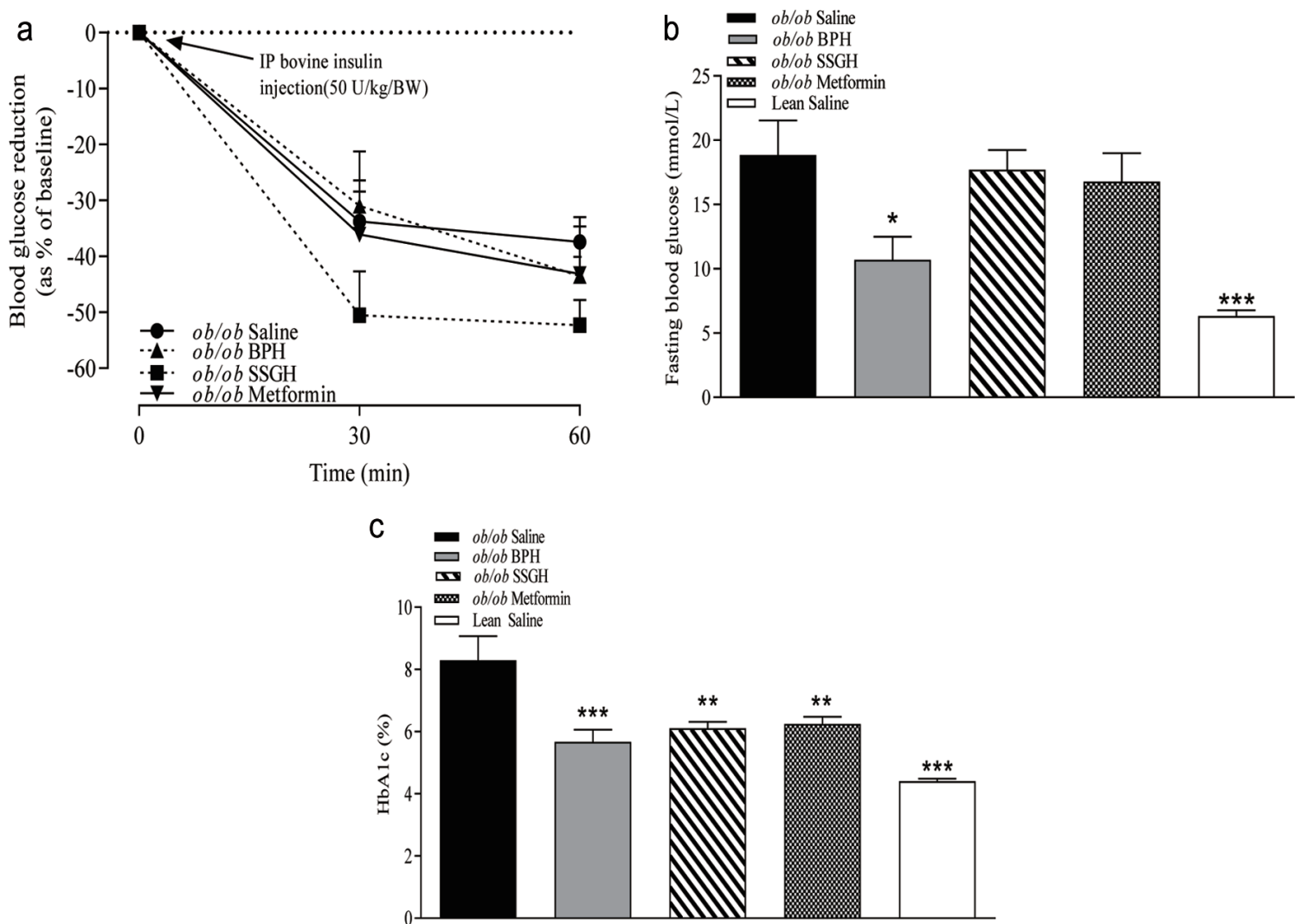

Figure 4. The effect of fish hydrolysate treatment on (a) insulin sensitivity and (b) integrated area under the curve (AUC), (c) fasting blood glucose and (d) glycated haemoglobin $\left(\mathrm{HbA}_{1 \mathrm{c}}\right)$. Mice were treated with hydrolysate $(50 \mathrm{mg} / \mathrm{kg}$ bodyweight), saline, or metformin (200 mg/kg bodyweight) for 27 days. Insulin sensitivity was assessed following i.p. administration of bovine insulin $(50 \mathrm{U} / \mathrm{kg} / \mathrm{BW}$; A). Fasting glucose and glycated haemoglobin were assessed following extraction of terminal whole blood samples (c, d)Values represent mean \pm S.E.M. $(n=8) .{ }^{*} p<0.05,{ }^{* *} p<0.01, * * * p<0.001$ versus (ob/ob) saline control. BPH: boarfish protein hydrolysate; SSGH: salmon skin gelatin hydrolysate.

indicating SSGH might have increased alternative insulin independent antidiabetic effects, potentially through increased insulin re-sensitisation in skeletal muscle, adipose tissue, or liver (Dimitriadis et al., 2011). This point was corroborated by the improved terminal insulin sensitivity observed with SSGH (Figure 4a).

One of the clinical tests used for determination of T2DM progression is a glucose tolerance test (GTT). Glucose intolerance is a characteristic of T2DM and is often coupled with insulin resistance and impaired fasting glucose (Chatterjee et al., 2017). Both oral and i.p. glucose tolerance tests (GTT) were assessed herein. SSGH but not BPH caused a significant overall reduction in oral glucose excursion (Figure $3 b)$. Interestingly, this action was reversed when $\mathrm{BPH}$ and not SSGH caused a significant reduction in i.p. glucose tolerance (Figure 3d). An intriguing characteristic observed in both oral and i.p. glucose tolerance was that $\mathrm{BPH}$ exhibited significant glucose clearance by $90 \mathrm{~min}$. This anti-hyperglycaemic effect probably reflects the more potent insulinotropic response observed by $\mathrm{BPH}$ in Figure $2 \mathrm{c}$ and d compared to SSGH. Furthermore, animal stress is likely to be higher during an i.p. glucose tolerance test, as raised corticosterone levels were observed by Pilon and co-workers (Pilon et al., 2018) and (ob/ob) mice are known to have raised corticosterone secretion, impacting upon glucose uptake (Lindström, 2007). This corroborates evidence from within our group of the beneficial effect of BPH (Parthsarathy et al., 2018) and SSGH (Figure s1) on glycaemic control in healthy animals. Interestingly, SSGH was the only treatment to induce a noticeable improvement in insulin sensitivity (Figure 4a) however, this failed to reach significance. As the hyperinsulinaemia was clearly not alleviated by SSGH treatment in the (ob/ob) mice (Figure 2d), this data would suggest that this effect is due to improved insulin sensitivity rather than increased insulin clearance (Valera Mora et al., 2003). The exact mechanisms behind this improvement in insulin sensitivity were not investigated. However, we could speculate that this could potentially result from improved insulin receptor protein (IRS) function due to reduced plasma lipids (Figure 5), an anti-inflammatory response suppressing the release of TNF- $\alpha$, or secretion of adiponectin resulting in inhibition of hepatic glucose release and enhancement of glucose uptake in muscle and adipose (Saini, 2010). It is known that GLP-1 promotes anti-inflammatory effects in immune cells including suppression of TNF $\alpha$ as indicated in previous studies (Hahm et al. 2008; Yoon et al. 2020). Thus, anything that could enhance GLP-1 actions including the inhibition of DPP-4, such as evidenced here by SSGH, could therefore have an indirect action by suppressing TNF $\alpha$ and reducing inflammation through promoting GLP-1 receptor activation. The insulinotropic actions of BPH here could also assist in promoting antidiabetic actions by promoting insulin release, which is compromised in the $o b / o b$ mouse model of Type 2 diabetes.

The primary co-morbidity of diabetes is cardiovascular disease, which usually initially presents with the risk factor of dysregulated lipid metabolism (Einarson et al., 2018). Studies have also previously shown that people with T2DM and hyperlipidaemia often 

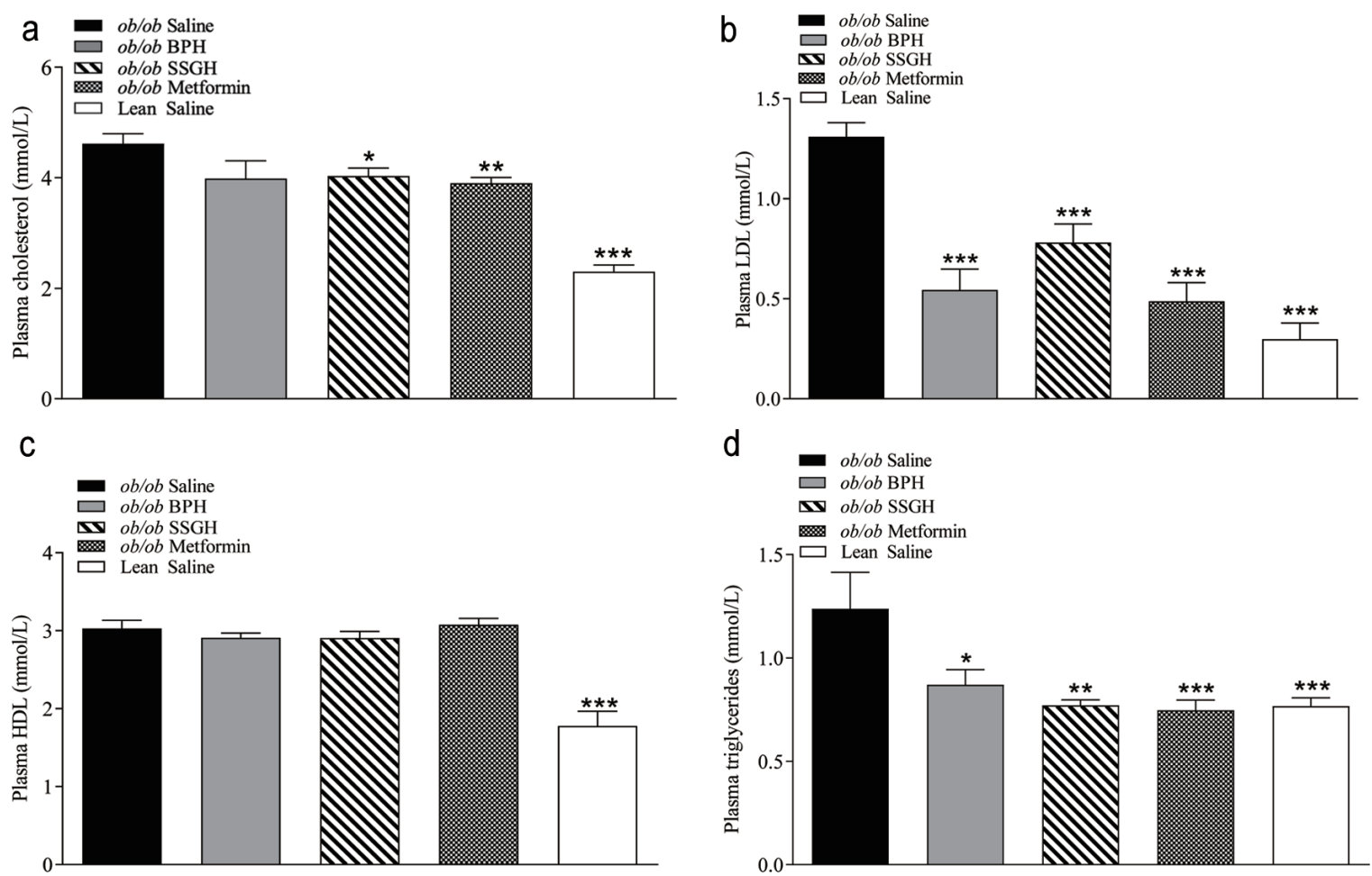

Figure 5. The effect of fish hydrolysate treatment on (a) total plasma cholesterol, (b) plasma LDL, (c) plasma HDL and (d) plasma triglycerides. Mice were treated with hydrolysate $(50 \mathrm{mg} / \mathrm{kg}$ bodyweight), saline, or metformin $(200 \mathrm{mg} / \mathrm{kg}$ bodyweight) twice daily for 27 days. Terminal plasma was collected following the treatment period and stored at $-20^{\circ} \mathrm{C}$ until required for lipid analysis by ILab 650 chemistry analyser $(a-d)$. Values represent mean \pm S.E.M. $(n=$ 8). ${ }^{*} p<0.05, * * p<0.01, * * * p<0.001$ versus ob/ob saline control. BPH: boarfish protein hydrolysate; SSGH: salmon skin gelatin hydrolysate.

also present with increasingly dysregulated glucose homeostasis (glucolipotoxicity) (Lytrivi et al., 2020). As shown in Figure 5b and $\mathrm{d}$, all treatment groups showed a positive impact upon plasma LDL and triglycerides, while SSGH also significantly reduced total cholesterol (Figure 5a). Increased TG's and LDL are known to be atherogenic, (Athyros et al., 2018) thus the significant improvement in the plasma lipid profile found in this study could indicate wider-reaching beneficial effects on diabetes co-morbidities, along with improved blood glucose management. The reduction in energy intake with all treatment groups was also interesting, however, this was not associated with any change in bodyweight gain. The $(o b / o b)$ mouse model lacks functioning leptin, compromising satiety, and leading to hyperphagia (Figure 1c), which is the driving force for the development of the obesity and diabetic characteristics (Lindström, 2007). Furthermore, leptin is fundamentally important in weight loss (Myers et al., 2010) thus in this model there was no change in bodyweight found despite a significant reduction in energy intake. The reduced energy intake without a corresponding reduction in bodyweight suggests that the energy intake reduction is due to a leptin-independent mechanism, however the only other mechanism examined in this study was total GLP-1 secretion, which only showed a significant increase with SSGH treatment (metformin showed a significant GLP-1 reduction), despite all treatment groups showing a reduction in energy intake. The primary focus of this study was to examine the anti-diabetic potential of two fish protein hydrolysates, however, a diet-induced obese model may be more appropriate for examining the long-term satiating potential, as there was an interesting change in energy intake (Figure 1c) which did not translate to changes in body weight, which may be related to the model selected.
There are limited chronic in vivo studies assessing the effect of protein hydrolysates on glycaemic control in mice, and if so, they are performed in various mouse models under different conditions and different biomarkers are assessed (Zhou et al. 2021). Therefore, it is very difficult to compare the results generated herein to other studies in terms of efficacy and differences in action.

It is well established that protein hydrolysates can beneficially regulate glycaemic control, with the extent of the response varying significantly depending on the primary sequence of the peptides and amino acids therein (Newsholme et al., 2006; HarnedyRothwell et al., 2020). In general, crude protein hydrolysates exert their bioactive effect through several mechanisms of action and it is likely that the results observed herein emerge from the beneficial synergistic effects arising from a number of peptides and/or amino acids within the protein hydrolysates. Both protein hydrolysates, utilised in this study, were shown to contain high quantities of low molecular weight components, in previously published articles, with $74 \%$ and $67 \%$ of the peptides/amino acids in BPH and SSGH $<1 \mathrm{kDa}$, respectively (Harnedy et al., 2018a; Parthsarathy et al., 2018). We have previously identified numerous peptides in a BPH generated with the same enzymes employed herein, which mediate insulin secretory activity from cultured pancreatic BRINBD11 cells and inhibit DPP-4 in a conventional in vitro and in situ cell-based (Caco-2) assay (Harnedy-Rothwell et al., 2020). Furthermore, one of the peptides identified, IPVDM, was shown to have multifunctional activity, inducing potent DPP-4 inhibition and insulin secretion (Harnedy-Rothwell et al., 2020).

While a comprehensive list of short peptides with DPP-4 inhibitory activity and information with regard to the influence of certain structural features on such activity is available, information 
in relation to the sequence of peptides mediating effects on other biomarkers of T2DM (e.g., insulin and GLP-1 stimulating activity) is limited. Salmon skin derived peptides, some of which are present in SSGH, have previously been shown to inhibit DPP-4 enzyme activity (Harnedy et al., 2017; Harnedy et al., 2018a; Jin et al., 2020 ; Li-Chan et al., 2012; Neves et al., 2017b). Furthermore, given that certain amino acids are known to promote insulin and/ or GLP-1 secretory activity, several peptides with potential insulinotropic and GLP-1 stimulatory activity have previously been identified in the SSGH under investigation in this study (Harnedy et al., 2018a). Amino acids such as Gln, Ala, Arg, Leu, Phe, Val, Ile, and Lys have been identified as strong insulin secretagogues, (Calbet and MacLean, 2002; Harnedy et al., 2018b; McClenaghan et al., 1996) while amino acids such as Glu, Ala, Ser and Gln, Gly, Asp, Leu and Met were shown to stimulate the release of GLP-1 from intestinal cells (Harnedy et al., 2018b). In addition, peptides, Leu-Gly-Gly, Gly-Leu and Gly-Pro) have been reported to stimulate the release of GLP-1 in vivo (Diakogiannaki et al., 2013). The high terminal plasma GLP-1 levels mediated by SSGH in Figure $1 \mathrm{~d}$, which was also observed in in vitro studies previously, are more than likely due to the high levels of Gly and Pro, identified in SSGH under investigation herein, which were 22.60 and 10.63 (g/100g), respectively (Harnedy et al., 2018a). Furthermore, these residues which make up the triad repeat sequence, Gly-X (mostly Pro)-Y, of gelatin were found in abundance in peptide sequences identified in the SSGH. Significantly lower levels of Gly and Pro (3.68 and $2.60(\mathrm{~g} / 100 \mathrm{~g})$, respectively) were found in the amino acid profile of a BPH generated under the same conditions, albeit at semi-pilot scale (Table s1), compared to the SSGH generated herein. This may explain the observed non-significant change in terminal plasma GLP-1 levels mediated by the BPH herein as was the case in previous in vitro studies (Parthsarathy et al., 2018). It is possible that gelatin-derived peptides and associated amino acids are present in the BPH as the hydrolysate was generated from a boarfish sample containing both the skin and meat. However, it is expected that gelatin-derived peptides would be present at low levels in the hydrolysate as the skin was only a minor component in the starting raw material.

Both fish protein hydrolysates contain significant quantities of key insulinotropic amino acids. Two of the most abundant free amino acids identified in SSGH utilised in this study include Arg and Phe at 1.15 and $1.07 \mathrm{~g} / 100 \mathrm{~g}$, respectively (Harnedy et al., 2018a). Following Gly and Pro, Arg and Ala are found as the third and fourth most abundant amino acids in SSGH at 7.80 and 7.81 $\mathrm{g} / 100 \mathrm{~g}$, respectively (Harnedy et al., 2018a). A BPH generated under the same conditions, albeit at semi-pilot scale, as the BPH generated herein was found to contain moderate to high levels of all insulin secretory residues (Supplementary Table 1). The presence of single amino acids with known insulinotropic activity may contribute to the potent insulinotropic activity observed herein with SSGH and BPH. However, further detailed studies beyond the scope of the present work would be required to investigate this aspect.

Finally, it is important to remark on the comparison between fish protein hydrolysate treatment and control (metformin) treatment. Metformin is often the first oral pharmaceutical treatment of choice for T2DM subjects. The anti-diabetic effects and mechanisms of action of metformin have been reviewed elsewhere (Rena et al., 2017). Broadly speaking, fish hydrolysate treatment resulted in similar improvements to metformin in blood glucose, plasma insulin, $\mathrm{HbA}_{1 \mathrm{c}}$, glucose tolerance and plasma lipid profile. Interestingly, BPH treatment had a markedly improved fasting blood glucose and plasma insulin response when compared to metformin, whereas SSGH treatment showed better insulin sensitivity. These results were especially promising, given that metformin dosage was quadruple that of hydrolysates, but the latter was used at a similar dose to that previously shown to be effective in $(o b / o b)$ mice (Green et al., 2006).

\section{Conclusions}

Both BPH and SSGH are effective for the management of diabetes in a genetically induced $(o b / o b)$ mouse model. Metabolic biomarkers and blood glucose showed improvements with hydrolysate treatment broadly similar to metformin. While further research is required to identify the peptides potentially responsible for the observed activity, it is believed that a synergistic effect arising from several short peptides and possibly amino acids within the hydrolysates are associated with the effects observed herein. Despite no effect on bodyweight, there was however a reduction in energy intake, indicating that these hydrolysates are potentially of interest for their effects on satiety if assessed in a more physiological situation such as high fat fed diet-induced obesity (DIO) mouse model. To the best of our knowledge, this is the first research to highlight the anti-diabetic potential of hydrolysates of boarfish protein hydrolysate in vivo and these in vivo findings add further weight to the evidence supporting the anti-diabetic potential of salmon skin gelatin hydrolysates. This data suggests that protein hydrolysates derived from the low-value marine processing by-product and fish species, namely salmon skin and boarfish have potent anti-diabetic potential and could be a suitable option for early management and prevention of T2DM. Furthermore, exploitation of these raw materials as sources of high-value functional peptide ingredients presents an opportunity for marine processors to add value to existing marine resources and to deal with side-streams, which are otherwise considered as waste. Translation of these findings to human studies could emphasise the attractiveness of boarfish and salmon skin gelatin as a high quality and sustainable protein source with potent bioactivity.

\section{Acknowledgments}

This research was funded under the National Development Plan, through the Food Institutional Research Measure (FIRM), administered by the Department of Agriculture, Food and the Marine, Ireland under grant number 13/F/467 and a Northern Ireland Department of Employment and Learning $\mathrm{PhD}$ scholarship for $\mathrm{Mr}$ Chris McLaughlin and Department of Finance and Education PhD scholarship for Mr Shaun Sharkey. The research was also part funded by the Science Foundation Ireland Infrastructure Fund and the Higher Education Authority under the Programme for Research in Third Level Institutions (cycle 4).

\section{Ethics statement}

All animal protocols were approved by the Ulster University, Animal Welfare and Ethical Review (AWERB) Committee and performed according to the UK Animals (Scientific Procedures) Act 1986 and EU Directive 2010/63EU.

\section{Conflict of interest}

There are no conflicts of interest to declare. 


\section{Author contributions}

FOH, VP and PHR designed the experiments, VP, CMcL and PHR performed the experiments, collected and analyzed the data, $\mathrm{CMcL}$ and RL wrote the draft manuscript. EMcS, PA, SS, RF and FOH supervised the work and read and edited the manuscript.

\section{Supplementary material}

Figure s1. The acute effect of salmon skin gelatin hydrolysate $(\mathrm{SSGH})$ on glucose tolerance and cumulative food intake in normal mice.

Table s1. Total and free amino acid composition of boarfish (Capros aper) protein hydrolysate generated with Alcalase and Flavourzyme at semi-pilot scale.

\section{Reference}

Athyros, V.G., Doumas, M., Imprialos, K.P., Stavropoulos, K., Georgianou, E., Katsimardou, A., and Karagiannis, A. (2018). Diabetes and lipid metabolism. Hormones 17: 61-67.

Calbet, J.A.L., and MacLean, D.A. (2002). Plasma glucagon and insulin responses depend on the rate of appearance of amino acids after ingestion of different protein solutions in humans. J. Nutr. 132: 2174-2182.

Chatterjee, S., Khunti, K., and Davies, M.J. (2017). Type 2 diabetes. Lancet 389: 2239-2251.

Cho, N.H., Shaw, J.E., Karuranga, S., Huang, Y., da Rocha Fernandes, J.D., Ohlrogge, A.W., and Malanda, B. (2018). IDF Diabetes Atlas: Global estimates of diabetes prevalence for 2017 and projections for 2045. Diabetes. Res. Clin. Pract. 138: 271-281.

Cudennec, B., Fouchereau-Peron, M., Ferry, F., Duclos, E., and Ravallec, R. (2012). In vitro and in vivo evidence for a satiating effect of fish protein hydrolysate obtained from blue whiting (Micromesistius poutassou) muscle. J. Funct. Foods 4: 271-277.

Diakogiannaki, E., Pais, R., Tolhurst, G., Parker, H.E., Horscroft, J., Rauscher, B., Zietek, T., Daniel, H., Gribble, F.M., and Reimann, F. (2013). Oligopeptides stimulate glucagon-like peptide-1 secretion in mice through proton-coupled uptake and the calcium-sensing receptor. Diabetologia 56: 2688-2696.

Dimitriadis, G., Mitron, P., Lambadiari, V., Maratou, E., and Raptis, S.A. (2011). Insulin effects in muscle and adipose tissue. Diabetes. Res. Clin. Pract. 93: S52-S59.

Drummond, E., Flynn, S., Whelan, H., Nongonierma, A.B., Holton, T.A., Robinson, A., Egan, T., Cagney, G., Shields, D.C., Gibney, E.R., Newsholme, P., Gaudel, C., Jacquier, J.C., Noronha, N., Fitzgerald, R.J., and Brennan, L. (2018). Casein Hydrolysate with Glycemic Control Properties: Evidence from Cells, Animal Models, and Humans. J. Agric. Food Chem. 66: 4352-4363.

Einarson, T.R., Acs, A., Ludwig, C., and Panton, U.H. (2018). Prevalence of cardiovascular disease in type 2 diabetes: A systematic literature review of scientific evidence from across the world in 2007-2017. Cardiovasc. Diabetol. 17: 1-19.

FAO (Food and Agriculture Organization of the United Nations). (2020). The State of World Fisheries and Aquaculture 2020. Sustainability in action. Rome. Available from: https://www.fao.org/3/ca9229en/ CA9229EN.pdf.

Flatt, P.R., and Bailey, C.J. (1981). Abnormal plasma glucose and insulin responses in heterozygous lean (ob/+) mice. Diabetologia 20: 573-577.

Green, B.D., Irwin, N., Duffy, N.A., Gault, V.A., O'Harte, F.P.M., and Flatt, P.R. (2006). Inhibition of dipeptidyl peptidase-IV activity by metformin enhances the antidiabetic effects of glucagon-like peptide-1. Eur. J. Pharmacol. 547: 192-199.

Hahm, E., Lee, Y.S., and Jun, H.S. (2008). Suppressive effects of glucagonlike peptide-1 on interferon-gamma-induced nitric oxide production in insulin-producing cells is mediated by inhibition of tumor necrosis factor-alpha production. J. Endocrinol. Invest. 31: 334-40.

Harnedy, P.A., O'Keeffe, M.B., and FitzGerald, R.J. (2017). Fractionation and identification of antioxidant peptides from an enzymatically hydrolysed Palmaria palmata protein isolate. Food Res. Int. 100: 416-422.

Harnedy, P.A., Parthsarathy, V., McLaughlin, C.M., O’Keeffe, M.B., Allsopp, P.J., McSorley, E.M., O'Harte, F.P.M., and FitzGerald, R.J. (2018a). Atlantic salmon (Salmo salar) co-product-derived protein hydrolysates: A source of antidiabetic peptides. Food Res. Int. 106: 598-606.

Harnedy, P.A., Parthsarathy, V., McLaughlin, C.M., O’Keeffe, M.B., Allsopp, P.J., McSorley, E.M., O’Harte, F.P.M., and FitzGerald, R.J. (2018b). Blue whiting (Micromesistius poutassou) muscle protein hydrolysate with in vitro and in vivo antidiabetic properties. J. Funct. Foods. 40: 137-145.

Harnedy-Rothwell, P.A., Khatib, N., Sharkey, S., Lafferty, R.A., Gite, S., Whooley, J., O'Harte, F.P., and FitzGerald, R.J. (2021b). Physicochemical, Nutritional and In Vitro Antidiabetic Characterisation of Blue Whiting (Micromesistius poutassou) Protein Hydrolysates. Mar. Drugs. 19: 383.

Harnedy-Rothwell, P.A., McLaughlin, C.M., Crowe, W., Allsopp, P.J., McSorley, E.M., Devaney, M., Whooley, J., McGovern, B., Parthsarathy, P., O'Harte, F.P.M., and FitzGerald, R.J. (2021a). Stability to thermal treatment of dipeptidyl peptidase-IV inhibitory activity of a boarfish (Capros aper) protein hydrolysate when incorporated into tomato based products. Int. J. Food Sci. Technol. 56: 158-165.

Harnedy-Rothwell, P.A., McLaughlin, C.M., O'Keeffe, M.B., Le Gouic, A.V., Allsopp, P.J., McSorley, E.M., Sharkey, S., Whooley, J., McGovern, B., O'Harte, F.P.M., and FitzGerald, R.J. (2020). Identification and characterisation of peptides from a boarfish (Capros aper) protein hydrolysate displaying in vitro dipeptidyl peptidase-IV (DPP-IV) inhibitory and insulinotropic activity. Food Res. Int. 131: 108989.

Hsieh, C.H., Wang, T.Y., Hung, C.C., Chen, M.C., and Hsu, K.C. (2015). Improvement of glycemic control in streptozotocin-induced diabetic rats by Atlantic salmon skin gelatin hydrolysate as the dipeptidylpeptidase IV inhibitor. Food Funct. 6: 1887-1892.

Jin, R., Teng, X., Shang, J., Wang, D., and Liu, N. (2020). Identification of novel DPP-IV inhibitory peptides from Atlantic salmon (Salmo salar) skin. Food Res. Int. 133: 109161.

Kalra, R., Parcha, V., Patel, N., Bhargava, A., Booker, KS., Arora, G., and Arora P. (2021). Increased awareness, inadequate treatment, and poor control of cardiovascular risk factors in American young adults: 2005-2016. Eur J Prevent. Cardiol. 28:304-312.

Le Pape, O., Bonhommeau, S., Nieblas, A.E., and Fromentin, J.M. (2017). Overfishing causes frequent fish population collapses but rare extinctions. Proc. Natl. Acad. Sci. USA 114: E6274.

Li-Chan, E.C.Y., Hunag, S.L., Jao, C.L., Ho, K.P., and Hsu, K.C. (2012). Peptides derived from Atlantic salmon skin gelatin as dipeptidyl-peptidase IV inhibitors. J. Agric. Food Chem. 60: 973-978.

Lindström, P. (2007). The physiology of obese-hyperglycemic mice [ob/ob mice]. Sci. World J. 7: 666-685.

Lytrivi, M., Castell, A.L., Poitout, V., and Cnop, M. (2020). Recent insights into mechanisms of $\beta$-cell lipo- and glucolipotoxicity in type 2 diabetes. J. Mol. Biol. 432: 1514-1534.

McClenaghan, N.H., Barnett, C.R., O'Harte, F.P.M., and Flatt, P.R. (1996). Mechanisms of amino acid-induced insulin secretion from the glucose-responsive BRIN-BD11 pancreatic B-cell line. J. Endocrinol. 151: 349-357.

Myers, M.G., Leibel, R.L., Seeley, R.J., and Schwartz, M.W. (2010). Obesity and leptin resistance: Distinguishing cause from effect. Trends Endocrinol. Metab. 21: 643-651.

Neves, A.C., Harnedy, P.A., O'Keeffe, M.B., and FitzGerald, R.J. (2017a). Bioactive peptides from Atlantic salmon (Salmo salar) with angiotensin converting enzyme and dipeptidyl peptidase IV inhibitory, and antioxidant activities. Food Chem. 218: 396-405.

Neves, A.C., Harnedy, P.A., O'Keeffe, M.B., Alashi, M.A., Aluko, R.E., and FitzGerald, R.J. (2017b). Peptide identification in a salmon gelatin hydrolysate with antihypertensive, dipeptidyl peptidase IV inhibitory and antioxidant activities. Food Res. Int. 100: 112-120.

Newsholme, P., Brennan, L., and Bender, K. (2006). Amino acid metabolism, $\beta$-cell function, and diabetes. Diabetes 55: S39-S47.

Nilsson, C., Raun, K., Yan, F.F., Larsen, M.O., and Tang-Christensen, M. (2012). Laboratory animals as surrogate models of human obesity. Acta Pharmacol. Sin. 33: 173-181.

Nongonierma, A.B., and FitzGerald, R.J. (2019). Features of dipeptidyl pepti- 
dase IV (DPP-IV) inhibitory peptides from dietary proteins. J. Food Biochem. 43: 1-11.

Parthsarathy, V., McLaughlin, C.M., Harnedy, P.A., Allsopp, P.J., Crowe, W., McSorley, E.M., O'Harte, F.P.M., and FitzGerald, R.J. (2018). Boarfish (Capros aper) protein hydrolysate has potent insulinotropic and GLP1 secretory activity in vitro and acute glucose lowering effects in mice. Int. J. Food Sci. Technol. 54: 271-281.

Pilon, G., Ruzzin, J., Rioux, L.E., Lavigne, C., White, P.J., Frøyland, L., Jacques, H., Bryl, P., Beaulieu, L., and Marette, A. (2011). Differential effects of various fish proteins in altering body weight, adiposity, inflammatory status, and insulin sensitivity in high-fat-fed rats. Metabolism 60: 1122-1130.

Pilon, S., Holloway, A.C., and Thomson, E.M. (2018). Metabolic, stress, and inflammatory biomarker responses to glucose administration in Fischer-344 rats: intraperitoneal vs. oral delivery. J. Pharmacol. Toxicol. Methods 90: 1-6.

Rena, G., Hardie, D.G., and Pearson, E.R. (2017). The mechanisms of action of metformin. Diabetologia 60: 1577-1585.

Rivero-Pino, F., Espejo-Carpio, F.J., and Guadix, E.M. (2020). Antidiabetic Food-Derived Peptides for Functional Feeding: Production, Functionality and In Vivo Evidences. Foods 9: 983.

Roblet, C.R., Akhtar, M.J., Mikhaylin, S., Pilon, G., Gill, T., Marette, A., and Bazinet, L. (2016). Enhancement of glucose uptake in muscular cell by peptide fractions separated by electrodialysis with filtration membrane from salmon frame protein hydrolysate. J. Funct. Foods. 22:
$337-346$.

Saini, V. (2010). Molecular mechanisms of insulin resistance in type 2 diabetes mellitus. World J. Diabetes 1: 6875.

Sharkey, S.J., Harnedy-Rothwell, P.A., Allsopp, P.J., Hollywood, L.E., FitzGerald, R.J., and O'Harte, F.P.M. (2021). A narrative review of the antihyperglycaemic and satiating effects of fish protein hydrolysates and their bioactive peptides. Mol. Nutr. Food Res. 64: 2000403.

Valera Mora, M.E., Scarfone, A., Calvani, M., Greco, A.V., and Mingrone, G. (2003). Insulin Clearance in Obesity. J. Am. Coll. Nutr. 22: 487-493.

Välimaa, A.L., Mäkinen, S., Mattila, P., Marnila, P., Pihlanto, A., Mäki, M., and Hiidenhovi, J. (2019). Fish and fish side streams are valuable sources of high-value components. Food Qual. Saf. 3: 209-226.

Yoon, G., Kim, Y.K., and Song, J. (2020). Glucagon-like peptide-1 suppresses neuroinflammation and improves neural structure. Pharmacol. Res. 152: 104615.

Zhou, X., Chai, L., Wu, X., Wang, Y., Li, S., and Chen, J. (2021). Anti-diabetic properties of bioactive components from fish and milk. J. Funct. Foods 85: 104669.

Zhu, C.F., Peng, H.B., Liu, G.Q., Zhang, F., and Li, Y. (2010). Beneficial effects of oligopeptides from marine salmon skin in a rat model of type 2 diabetes. Nutrition 26: 1014-1020.

Zhu, C.F., Zhang, W., Mu, B., Zhang, F., Lai, N.N., Zhou, J.X., Xu, A.M., Liu, J.G., and Li, Y. (2017). Effects of marine collagen peptides on glucose metabolism and insulin resistance in type 2 diabetic rats. J. Food Sci. Technol. 54: 2260-2269. 